\title{
Dialética temporal na narrativa de uma vida com uma doença rara ${ }^{1}$
}

\section{Dialectique temporelle dans le récit de soi vivant avec une maladie rare}

\section{Temporal dialetics in the narrative of a life with a rare disease}

\author{
Martine Janner Raimondi*
}

\begin{abstract}
RESUMO
O presente artigo visa identificar as dinâmicas dialéticas temporais e as tensões presentes na narrativa pessoal, na narração de histórias e nos processos de compreensão de si mesmo e do mundo que são revelados na autobiografia (DELORY-MOMBERGER, 2014) de narrativas solicitadas a pacientes voluntários, portadores de uma doença autoimune rara: lúpus eritematoso sistêmico e esclerodermia, escritas por eles mesmos. Na esteira dos trabalhos de Tourette-Turgis (2013) e de Flora (2013), esta pesquisa, denominada E-Fom Innov (2016-2018) e liderada pelo Prof. Farge-Bancel, deu voz às pessoas envolvidas para poder compreender as experiências de uma vida com uma doença rara. É no âmbito da fenomenologia inspirada em Husserl $(1964 ; 1980)$, particularmente na sua concepção de dinâmica do tempo (PICARD, 2009), do trabalho de Ricoeur (1985; 2005) e de Romano (1999) sobre as questões de tempo narrado e eventos, que a dialética temporal em ação na narrativa em primeira pessoa será examinada. Assim, no processo de patologização indo da anormalidade à doença, vamos examinar o(s) papel(is) do tempo diante da inquietude do eu, antes de concluir com uma redefinição do cuidado (WORMS, 2014).
\end{abstract}

Palavras-chave: Autobiografia. Autopatografia. Doença crônica. Experiências. Abordagens narrativas. Cuidado. Medicina.

1 Traduzido por Camila Aloisio Alves. E-mail: camila.aloisioalves@gmail.com.

*Université de Sorbonne. Paris Nord, UR, França. E-mail: martine.janner@univ-paris13fr - https://orcid.org/0000-0001-7781-8685 


\title{
RÉSUMÉ
}

Cet article vise à identifier les dynamiques et les tensions dialectiques temporelles en jeu dans le récit de soi, la narration et les processus de compréhension de soi et du monde qui se révèlent dans l'autobiographie (DELORY-MOMBERGER, 2014) des récits sollicités et rédigés par des patients volontaires, atteints d'une maladie rare auto-immune : le lupus érythémateux systémique et sclérodermie. Cette recherche appelée $E$-Fom Innov (2016-2018), portée par le Pr. Farge-Bancel, donne ainsi voix aux personnes concernées, pour donner à entendre leurs expériences du vivre avec une maladie rare, dans le sillage de Tourette-Turgis (2013) et Flora (2013). C'est dans le cadre de la phénoménologie qui s'inspire de Husserl (1964; 1980), notamment sur sa conception dynamique du temps (PICARD, 2009), des travaux de Ricoeur (1985; 2005) et de Romano (1999) sur les enjeux du temps raconté et d'événement que sera examinée la dialectique temporelle à l'œuvre dans le récit de première personne. Ainsi, dans le processus de pathologisation allant de l'anomalie à la maladie, nous examinerons le(s) rôle(s) du temps dans l'inquiétude du soi, avant de conclure sur une redéfinition du prendre soin (WORMS, 2014).

Mots clés : Autobiographie. Autopathographie. Maladie chronique. Expériences. Approches narratives. Soin. Médecine.

\begin{abstract}
This article aims to identify the dynamics and temporal dialectical tensions at play in self-narration, narration and the processes of understanding the self and the world that are revealed in the autobiography (DELORYMOMBERGER, 2014) of the solicited and written by volunteer patients with a rare autoimmune disease: systemic lupus erythematosus and scleroderma. This research called E-Fom Innov (2016-2018), led by Prof. Farge-Bancel, thus gives voice to those concerned, to give voice to their experiences of living with a rare disease, in the wake of Tourette-Turgis (2013) and Flora (2013). It is within the framework of the phenomenology which is inspired by Husserl $(1964 ; 1980)$, in particular on his dynamic conception of time (PICARD, 2009), the work of Ricoeur (1985; 2005) and of Romano (1999) on the stakes of the time told and of the event that will be examined by the temporal dialectic at work in the first-person narrative. Thus, in the pathologization process from abnormality to disease, we will examine the role (s) of time in self-anxiety, before concluding on a redefinition of taking care (WORMS, 2014).
\end{abstract}

Keywords: Autobiography. Autopathography. Chronic disease. Experiences. Narrative approaches. Care. Medicine. 


\section{Introdução}

O desafio deste dossiê está em identificar a dinâmica e as tensões entre as temporalidades da narrativa, os efeitos dessa narrativa e os processos resultantes da compreensão de si mesmo e do mundo através da dimensão biográfica. $\mathrm{Na}$ tentativa de dar algumas respostas a este problema, focaremos nas narrativas escritas por pacientes portadores de uma doença autoimune rara: a esclerodermia e o lúpus eritematoso sistêmico no contexto de uma pesquisa destinada a compreender seus pontos de vista sobre a experiência do adoecimento, do diagnóstico e do tratamento. Gostaríamos de agradecer especialmente a cada um dos 28 pacientes que estiveram envolvidos nesta pesquisa. Considerados como co-pesquisadores (18 sofrem de esclerodermia; 10 de lúpus), suas autopatografias (ROSSI, 2019) constituem o próprio coração da vertente das ciências sociais e humanas $^{2}$ desta pesquisa, que foi liderada pelo Dr. Farge-Bancel ${ }^{3}$ e que incluiu pesquisadores em ciências da educação sob a supervisão das professoras $\mathrm{C}$. Delory-Momberger e C. Tourette-Turgis ${ }^{4}$. Na esteira dos trabalhos de TouretteTurgis (2013) e de Flora (2013), Jouet, Flora e Las Vergnas (2010), bem como da perspectiva de formação de pacientes-recursos e de profissionais de saúde da Universidade de Montreal, buscou-se dar voz aos pacientes e compreender suas experiências de vida.

O estudo desenvolveu-se segundo a abordagem da pesquisa biográfica (DELORY-MOMBERGER, 2009; 2014), cujo objetivo não é apenas coletar a história de vida do sujeito, solicitando-lhe com moderação a fim de limitar o risco de tornar penosa a construção da narrativa. Nesta abordagem, o pesquisador não se posiciona como um levantador de dados, mas como um interlocutor que dá uma atenção especial ao valor da narrativa de si, na medida em que ela constitui um processo central na construção do indivíduo e na produção da esfera social (NIEWIADOMSKI, 2019). Entretanto, solicitar uma autopatografia ainda é uma tarefa bastante rara na França, sem dúvida devido à pressuposta relação positiva com a escrita, isso sem mencionar as dificuldades inerentes ao uso da escrita

2 Agradecemos também os profissionais de saúde, os membros da Associação Francesa de Lúpus e outras doenças autoimunes e raras.

3 Esta pesquisa, liderada pela Dra. Farge Bancel, do Hospital Saint-Louis, AP-HP, certificado em 2017 como Centro de Referência para Doenças Autoimunes Sistêmicas Raras da Île de France, intitulada "EFORM-INNOV" (2016-2018) foi financiada e apoiada pela Fundação para Doenças Raras no âmbito do Programa "Ciências Humanas e Sociais \& Doenças Raras" (2014).

4 Profa. C. Delory-Momberger, Universidade Sorbonne Paris Nord, UR / Expérice, C. Tourette-Turgis, Universidade dos Pacientes, Pierre \& Marie Curie. 
especular, realizada com a ajuda de ferramentas digitais (BILLOUET, 2010). Cada co-pesquisador tinha um pesquisador de referência que acompanhou a construção narrativa e, uma vez que ela foi escrita e depositada na plataforma que reunia todos os participantes, os co-pesquisadores foram convidados a ler as histórias uns dos outros, com a possibilidade de deixar um comentário que complementaria as histórias a fim de reunir as experiências narradas. Os pesquisadores, por sua vez, foram então convidados a escrever uma primeira análise dirigida aos co-pesquisadores que acompanhavam. Posteriormente, os momentos de diálogo foram realizados por telefone ou na forma de entrevistas presenciais, para torná-los mais fluidos e acessíveis. A relevância da escolha de uma ferramenta de intercâmbio digital entre os pesquisadores e os copesquisadores que serviu de suporte à escrita, não será alvo de uma discussão neste artigo, ainda que mereça ser explorada e esclarecida, sobretudo face aos momentos de crises agudas da doença, que impossibilitaram a escrita, ou mesmo diante do que é conhecido como a quebra digital.

A fim de buscar responder à problemática colocada pelo dossiê, refinaremos, especificamente, as dimensões temporais em relação às experiências vividas e depois contadas, inscrevendo nossa reflexão no campo da filosofia prática, mais precisamente na fenomenologia de Husserl (1980), em particular através da leitura experimental feita por Depraz (2009), bem como fazendo referência ao trabalho de Ricoeur $(1985,2005)$ e Romano (1999) sobre as questões da narrativa do tempo e do evento, sem omitir trabalhos de doutorado sobre as experiências de pacientes crônicos (BARRIER, 2007; LECORDIER, 2019). Em suma, nossas reflexões se concentrarão na noção de cuidado com base nas reflexões de Worms (2014). No contexto deste artigo, examinaremos onde e como as dimensões temporais estão situadas nos dois textos de Louise, portadora da doença de lúpus, escritos com algumas semanas de intervalo. Como aponta Bourré-Tessier (2011) em sua tese de ciência médica, o lúpus é uma doença que faz parte das doenças crônicas, na qual o sistema imunológico da pessoa portadora ataca as células de seu próprio corpo, desenvolvendo inflamações que podem danificar vários órgãos. As pessoas experimentam o que se convencionou chamar de erupções de lúpus, que são sinais de crises inflamatórias. As mulheres são as mais afetadas, com uma prevalência estimada da doença, nos anos 2010, de 1 por 1.000 a 10.000. A doença pode ocorrer na faixa etária que vai dos 15 aos 50 anos.

Passemos, então, ao exame da dialética temporal que se coloca em ação quando se solicita uma narrativa em primeira pessoa. Em seguida, identificaremos o tempo da inquietude do eu através do exame da anomalia sofrida nos estágios iniciais da doença, antes do início do processo de patologização, transformando assim a anomalia inicial em uma anormalidade (LECORDIER, 2019) e fazendo 
a pessoa experimentar a radicalidade da sua própria temporalidade. Finalmente, discutiremos a importância do tempo e da narrativa nesta apreensão de si antes de fornecer algumas perspectivas em termos de cuidado.

\section{Solicitação da narrativa em primeira pessoa e cuidado de si: dialética temporal}

A solicitação de narrativas de pessoas diretamente envolvidas por um tema de pesquisa surgiu nos anos de 1920, no departamento de sociologia, mais tarde chamada de "Escola de Chicago", embora fosse "um empreendimento multifacetado, muito pragmático, fora dos padrões acadêmicos" (PENEFF, 1990, p. 36). Ou, como salienta Delory-Momberger (2019, p. 343): "na e através da narrativa, o sujeito realiza um ato de configuração e interpretação - de moldar e fazer sentido - da experiência vivida".

Trata-se precisamente de prestar atenção nas narrativas da experiência vivida em primeira pessoa. Breton (2020), na esteira das abordagens de Vermersch (1994) e Depraz (2011), especifica as expectativas de uma abordagem "em primeira pessoa", e não "na" primeira pessoa. No entanto, como aponta Depraz (2011): "Falar em primeira pessoa" significa, como afirma Vermersch "usar a palavra encarnada, ou seja, entrar em um regime de expressão que manifeste plenamente a realidade concreta de um contato com o que se vive no momento em que se formula. O discurso fornece indicações disso" (DEPRAZ, 2011, p. 62). Sem negar a importância de tal perspectiva, nossa pesquisa não incluiu tal exigência. O convite para dizer "como tudo isso (a doença) começou?" não pede uma descrição de uma quase experiência, como se fosse possível mergulhar no passado para revivê-lo, pois isso teria exigido uma abordagem e uma condução rigorosa e precisa da entrevista, como no caso da entrevista de explicitação ou de auto-explicitação, desenvolvida por Vermersch (1994) e Petitmengin (2010), em particular. Nosso objetivo situa-se, portanto, no nível da própria escrita da pessoa, com sua própria linguagem, suas palavras e sua fraseologia, a objetivação de um pensamento que é expresso e compartilhado, sem procurar exigir que a pessoa reviva suas experiências, nem ser capaz de dizer o que quer que seja sobre elas. Nosso postulado consiste mais em acolher a narrativa do co-pesquisador pelo que ela é: ou seja, sua narrativa tornada acessível aos seus pares e dirigida a nós, sem procurar saber se ela corresponde ou não ao que foi vivido. 
Nossa pesquisa está, portanto, na esteira de uma epistemologia que revisita os cânones da verdade fundada em provas experimentais e leis estatísticas da Medicina Baseada em Evidências, desenvolvendo abordagens da subjetividade para além do pensamento hipotético-dedutivo e dos raciocínios estatísticos. Esta pesquisa, particularmente desenvolvida no contexto de pessoas cujos padrões de vida diferem daqueles da maioria, coloca em relevo diferentes vozes (GILLIGAN, 2008), particularmente em relação ao sofrimento experimentado em seus corpos (HUSSERL, 1980), a sensibilidade das suas almas e aos cuidados. As provações impostas pelas deficiências e pelas doenças, especialmente crônicas e, a fortiori, raras, acentuam as dificuldades de "viver com"; elas tocam o corpo e com ele a consciência, como se estivessem em carne viva, provocando a preocupação consigo mesmo e, portanto, a preocupação com os cuidados de si. Na verdade, estes últimos são vividos durante remissão ou de um "viver com" que não agrave (muito) o estado de saúde do paciente. Ou, de fato, "vemos o cuidado (...) somente durante as provações que afetam a continuação de nossas vidas e que pode ameaçar interrompê-las" (WORMS, 2014, p. 141). Neste ponto, cabe citar a tese defendida em ciências da educação por Barrier (2007), que busca não só valorizar o ponto de vista do paciente, mas também a sua própria experiência enquanto doente para reconsiderar a relação de cuidado. Lecordier (2019) propõe, em seu trabalho de doutorado, de natureza sociológica, modelar as etapas de construção da trajetória da doença crônica no que diz respeito ao papel da norma e do fator tempo. "Das situações incomuns até os desconfortos inconvenientes, que se tornam mesmo insuportáveis, há graus de intensidade da anomalia que levam a perguntas para aqueles que as vivem" (LECORDIER, 2019, p. 16).

Propomos revisitar as etapas desta modelagem, indo da anomalia à doença, passando pela anormalidade, seguida da patologia a fim de identificar, através das dimensões temporais da narrativa dos pacientes, o curso de suas tomadas de consciência sobre as próprias experiências vividas com uma doença autoimune, rara. Em primeiro lugar, consideremos que, para Lecordier, foram de fato as narrativas orais dos pacientes que lhe permitiram desenvolver um modelo da trajetória da chamada doença crônica. Em segundo, essas narrativas também permitiram identificar uma falta de continuidade na doença "crônica", em que se alternam momentos de descanso, durante os quais o paciente se sente bem, com momentos de crise, que requerem intervenções e tratamentos mais específicos. É por isso que o autor se refere aos pacientes como "portadores intermitentes da doença (crônica)", indo até o ponto de questionar o status e o uso da própria noção de cronicidade e de "doença crônica" (LECORDIER, 2019, p. 15).

Da nossa parte, retomaremos a leitura das narrativas escritas dos pacientes portadores de doenças raras para identificar os aspectos temporais no seio das 
experiências vividas e retomadas nos textos, tanto no nível do conteúdo temático (BARDIN, 2013) em relação ao lugar consagrado ao eu, aos outros e ao mundo, marcado pelo tempo, quanto no nível do processo de consciência desencadeado de forma subjacente para identificar e transcrever os eventos, as experiências e os sentimentos configurados na narrativa. A partir destas identificações, que dão vida aos textos escritos pelos pacientes, tentaremos também compreender os diferentes significados do cuidado.

\section{O tempo de inquietude do si começa pela anomalia vivida, suportada, ao qual a narrativa escrita confere uma forma reatualizada}

Os sinais de alerta de uma doença crônica situam-se, antes de tudo, no nível da temporalidade da anomalia vivida e observada na carne, à qual a pessoa presta mais ou menos atenção no início e, à medida em que ela persiste, confere-lhe maior importância. Seguindo o exemplo de Marguerite, de 89 anos (LECORDIER, 2019, p. 161), eis o início do relato de Louise, que se lembra das primeiras sensações dolorosas e estranhas que teve aos vinte anos de idade. Ela as suporta, as retarda e tenta contrariá-las, mostrando-se mais forte do que elas, até que a intervenção e a inquietude da família desencadeiam uma preocupação e um cuidado consigo mesma.

Durante meu primeiro ano de faculdade em S. (1999-2000), minha primeira casa sem meus pais, muitas vezes eu me sentia muito cansada e de muito mau humor. Muitas vezes acordava com as articulações dos tornozelos, dos pulsos e dos dedos muito inchadas e dolorosas. Mas eu não havia contado a ninguém pensando que era normal! Por outro lado, desde o verão, quando eu era monitora de equitação, tratadora e treinadora de cavalos de corrida, minha enorme queimadura solar no rosto não desaparecia.

Quanto mais o tempo passava, pior eu me sentia física e moralmente. Mas para não mostrar nada, eu me violentava vivendo com um ritmo de estudante: muitas saídas noturnas, comida ruim... e fazendo muito esporte. No mês de março, quando meu pai comemorou seus 50 anos, um grande número de pessoas estava presente, inclusive um médico que me viu quando eu retornava de uma sessão esportiva (2 horas de tênis e $10 \mathrm{~km}$ de corrida), e ele lançou "você tem lúpus".

Minha mãe, que estava ao lado, ao saber, não reagiu bem, pois seu próprio pai havia morrido por causa disso (Louise). 
Este primeiro momento da anomalia pôde ser encontrado em todas as outras narrativas dos demais co-pesquisadores. Ele equivale a um tempo de provas e resistência, que precede e já anuncia uma potencial preocupação consigo mesmo. Ao tentar identificar os traços de consciência, no(s) momento(s) em que a anomalia vai da inquietude à preocupação consigo mesmo, parece que todas as narrativas dos co-pesquisadores, solicitados na pesquisa E-FormInnov, mostraram que eles foram capazes de significar em que momento e sob que formas concretas, vividas tudo começou. Entretanto, quando um evento ocorre, ainda que ele seja dramático, é raro que sejamos imediatamente capazes de responder a perguntas como "Como tudo começou?" e "O que e quem lhe ajudou ou não?".

Para Husserl (1964), a consciência aparece para si mesma somente através dos fenômenos que ela ordena no fluxo contínuo das coisas da vida, que nos acontecem ou que iniciamos, fazendo coexistir em um movimento sem fim as retenções de momentos passados, os momentos recém passados no presente com as pró-tensões de um futuro próximo ou mais distante. Husserl (1964, p. 97) examina "o fluxo de consciência absoluta, constitutiva do tempo". O tempo é então apreendido como "tempo das vivências", "tempo que aparece" à consciência, "tempo imanente do corpo e da consciência" (HUSSERL, 1964, p. 7). Picard (2009, p. 15) afirma: "o que faz com que a consciência se temporalize é que a cada instante surge um novo agora. Este último transforma assim o presente agora em um agora retido, implicado pelo novo agora que lhe dá seu significado e que ele próprio aparece como o significado do agora, a primeira data". Como Bernet (1987, p. 503) também aponta: “o que é notável [...] é que o que une e amarra estes diferentes fios do tempo em uma trama contínua é o presente".

Assim, a experiência perceptiva do presente estaria relacionada à lembrança e expectativa, ao passado e futuro, enquanto a experiência perceptiva do passado, bem como do próprio futuro, não faria sentido. $\mathrm{O}$ fenômeno da consciência revelado nas narrativas dos pacientes está relacionado ao processo contínuo do fluxo do tempo, revelando assim um trabalho de presentificação que permite compreender a irredutibilidade e a unicidade absoluta da narrativa produzida no aqui e agora. O ser individual é, portanto, temporal, e o tempo a que se refere não pode ser entendido como um recipiente estático; além disso, parece dinâmico em sua dialética entre as retenções do passado e as expectativas do futuro envolvendo incessantes engendramentos e modificações que a narrativa escrita cristaliza em uma forma estabelecida em um determinado momento. Assim, a narrativa atualiza as retenções de momentos passados, não sem levar em conta o presente e até mesmo o futuro. 
Esse futuro pode levar em conta os próprios objetivos do projeto de pesquisa, o que sublinha o interesse em contar histórias a outras pessoas, quer sejam outros doentes portadores da mesma doença, quer sejam cuidadores que os acompanham. A "raridade" de uma doença só acentua esta preocupação em divulgar as histórias das experiências vividas devido ao adoecimento a fim de torná-lo mais conhecido em seus meandros.

\section{A patologização da anomalia como um processo de a-normalização precipita as sensações de experimentar a própria temporalidade}

A anomalia é seguida pela anormalidade, que é identificada após a intervenção de outras pessoas, parentes ou profissionais de saúde, que então recomendam diferentes abordagens e exames a fim de chegar a um diagnóstico médico. De fato, como aponta Lecordier (2019, p. 164): “a particularidade da anomalia é que ela é gerada na intimidade da consciência, antes de ser exteriorizada ou pelo menos percebida pelos outros". Ela se mostrará "anormal" quando for compartilhada com os outros". Louise evoca a "brutalidade do anúncio do lúpus" através das expressões que usa: "ele me viu quando eu retornava de uma sessão esportiva (2 horas de tênis e $10 \mathrm{~km}$ de corrida), $e$ lançou "você tem lúpus".

Entretanto, um pouco mais adiante no texto, a narrativa especifica que este médico já havia feito muitas perguntas, olhou mais de perto suas articulações e seu rosto, antes de aconselhá-la a ir ver "rapidamente [seu] clínico geral para que ele pudesse prescrever exames de sangue". O texto revela assim que a ordem de enunciação ressoa com o que fora experienciado emocionalmente no momento do anúncio, e não com a ordem cronológica dos fatos vividos.

Aprendemos que a raridade da doença e consequentemente o seu desconhecimento, inclusive entre os médicos, quase atrasou o processo do tratamento: "O médico não queria, dizendo-me que eu sou jovem, praticante de esporte e que era qualquer coisa. Nós insistimos (especialmente minha mãe), e é claro que os resultados deram positivos com um inicio de danos renais". O especialista que havia tratado o seu avô (que morreu da mesma doença) entrou em contato com ela para falar dos aspectos internos e externos da patologia e para iniciar um primeiro tratamento: 
O professor que acompanhou o meu avô em Paris queria me encontrar para as suas pesquisas genealógicas... e lá me explicaram muitas coisas sobre como viver com isso... mas eu não queria ouvir nada e disse para mim mesma que ia agir como se nada tivesse acontecido e que eu seria mais forte que lúpus... infelizmente não funcionou e o tratamento que eu estava fazendo me fez ter uma imagem ainda pior de mim mesmo! Eu tinha literalmente inchado com cortisona e assim que podia, eu parava o tratamento, o que fez a doença voltar ainda mais! (Louise).

Os efeitos do primeiro tratamento acentuaram os sentimentos de desconforto e de raiva de si mesma, experienciados por Louise. A anomalia inicial que ela experimentou, em um passado não muito distante, torna-se para o médico um "desvio das normas" de saúde diante do qual convém intervir a fim de regular o destino da própria doença e limitar uma evolução potencialmente grave. As experiências no tratamento das doenças permitem estabelecer normas com relação à evolução da própria doença, que servem como referências para acentuar ou influenciar os cuidados prestados e suas modalidades. Porém, no caso das doenças raras, sua evolução ainda não é suficientemente conhecida para ser claramente antecipada. Continua incompleto, o que marca ainda mais o período de incerteza para o paciente. Para Louise, os efeitos do tratamento acentuam esta lacuna em relação ao que ela pensa ser "normal" para os outros, cujos olhares e supostos julgamentos foram por ela internalizados. Suas iniciativas a levam a suspender seu tratamento assim que ela julga que pode fazê-lo. Poderíamos considerar o paradoxo do seu gesto relacionado, por um lado, ao desejo de manter vivo seu poder de ação para além dos riscos envolvidos; e, por outro, a uma submissão ainda maior à imagem de um corpo que ela deseja que seja "normal" diante de um suposto olhar dos outros. De fato, como salienta Worms (2014, p. 96), citando Barthes (2002): "Meu corpo é para mim a imagem que acredito que o outro tem deste corpo, e assim toda uma tática é instituída entre os seres através dos seus corpos [...] o medo do ridículo, a possibilidade de exercer uma espécie de maldade sobre o corpo do outro". O relato de Louise continua indicando que ela tomou consciência, no momento em que escreveu o relato, dos efeitos nocivos dessas paradas, não apenas sobre o futuro da doença, mas também sobre o "viver com" a doença.

Louise escreveu seu texto em dois momentos, com algumas semanas de intervalo. Em seu segundo texto, ela volta ao momento do anúncio da doença, especificando seus sentimentos, particularmente no intervalo entre o seu estado de fadiga, o sofrimento que experimenta em seu no interior e a imagem de si mesma que espera ser capaz de dar aos outros, a partir das expectativas que 
ela imagina. Sua raiva parece profunda, quase visceral, e inclui um ódio ao seu corpo e a si mesma. Usando metáforas, ela evoca então uma "bola de raiva" contra si mesma, sentindo-se "invadida por um monstro que quer me destruir", o que a leva a pensar várias vezes em suicídio. Como um grito, ela dá voz à sua angústia e inquietação.

Como é possível considerar um cuidado terapêutico se tal grito não for ouvido? A introspecção e o compromisso com a escrita mostrados na história de Louise vão ao ponto de evocar o abuso sexual de que ela foi vítima alguns meses antes do anúncio de sua doença. A evocação quase tímida do estupro aparece no segundo texto, como se fosse um desvio de uma frase, e, mesmo assim, está significada dando a entender que a sua raiva é ainda mais forte. Ela dá-se conta ao escrever quando ocorrem as crises de lúpus.

Quando me diagnosticaram com esta doença, sentia-me muito cansada fisicamente (acordar era cada vez mais complicado), dores físicas, falta de motivação...), mas vinda de uma família onde a preguiça e a escuta do corpo são tabus, decidi fingir que não tinha lúpus. Moralmente, eu também não estava bem: eu me sentia perdida por não ter o controle do meu corpo. Eu desejava ter podido mudar.. Eu me detestava. Mas este sentimento já existia há alguns meses antes do diagnóstico, porque eu tinha sido vítima de estupro (5 meses antes do diagnóstico). Lembro-me de um sentimento de ódio contra mim mesma uma bola de raiva crescendo às vezes dentro da minha barriga. Eu podia, e ainda posso, ver que este sentimento de raiva profunda precede os ataques de lúpus. Reagi de forma destrutiva: eu tinha uma crise articular e então saía para correr ou jogava tênis, me sentia totalmente exausta quando estava festejando com os meus amigos... Enquanto que, de um ponto de vista externo, eu estava trabalhando para não mostrar minha dor, eu estava completamente sobrecarregada por dentro e me senti invadida por um monstro tentando me destruir. Várias vezes pensei em suicídio, mas no final sempre encontrei um pouco de otimismo. Em seguida, disse para mim mesma que com o tratamento eu iria melhorar..., mas nos primeiros meses de tratamento, com a cortisona e os imunossupressores, eu inchei, a máscara não desaparecia e eu estava ficando doente o tempo todo. Na minha vida cotidiana, eu ouvia regularmente "ah, lamento ter 18 anos, você tem sorte de estar aproveitando a fase da despreocupação e da saúde..." Eu tinha ainda mais raiva de mim do que antes e me sentia culpada por não estar no controle. Eu não queria falar sobre isso com minha família, imaginava que meu pai não entenderia e me pressionaria a agir como se tudo estivesse bem, enquanto minha mãe tinha tomado posse da minha doença e eu não queria deixá-la ainda mais ansiosa. Quando eu não me 
sentia bem, que eu sentia a crise vir, não ia me consultar. Eu esperava até ficar realmente mal para ir ao hospital, onde eu ficava hospitalizada regularmente (Louise).

As internações parecem ser o último recurso "Eu esperava até ficar realmente mal", mas elas ressoam como períodos de descanso durante os quais Louise aceita ser cuidada, talvez até mesmo, tenha sido esta a sua maneira de aceitar ser cuidada. Louise continua a escrever sua narrativa e retoma a angústia que sentiu enquanto esperava os resultados dos exames. Entre o medo e o desejo de saber, este tempo de espera, podemos ouvi-lo como um evento no sentido de Romano (2012, p. 162-163):

O evento sempre se anuncia sob seu próprio horizonte de inteligibilidade, como um enigma que contém tanto a chave, quanto o código: manifestando-se ao mesmo tempo pelo significado e pelo absurdo do que parece, à primeira vista, incompreensível, e pelo excesso de um significado do qual é a origem, aberto, como tal, a uma tarefa hermenêutica de direito inesgotável.

De fato, este tempo de espera por resultados é um tempo aberto a construções plurais, tanto incompreensíveis, quanto aberta a uma infinidade de significados, deixando a pessoa que o experimenta presa a movimentos dialéticos de consciência que vêm e vão com as retenções do passado e com as previsões que passam pelo momento presente, cuja presentificação assume contornos de dramatização, pois o que se inaugura é uma doença para toda a vida.

Entre este momento e os resultados dos exames, eu estava muito ansiosa por dentro e queria saber, mas tinha muito medo... Não contei sobre isso para as pessoas que me rodeavam... Eu queria parecer forte (Louise).

Se, como aponta Housset (1997, p. 16): "Toda vida consciente é uma vida temporal e toda vida consciente só pode ser a de um 'eu", então, a narrativa de Louise refere-se bem a esses movimentos de consciência da temporalidade da sua própria vida, diante de um "eu" que se coloca, afirma ou se submete aos eventos que surgem. 


\section{Experimentar a temporalidade de si na doença rara "crônica": o papel da narração}

Para Picard (2009, p. 13), o ser individual só pode ser pensado como "durante (o ser enquanto ser é temporal, o tempo é o ser mesmo)". Entretanto, o evento da doença, a fortiori, quando vem a ser "crônica" e rara, provoca uma precipitação do tempo, como se a vida se acelerasse brutalmente. As narrativas dão voz a estes movimentos de consciência e de pensamento que buscam sentido para permitir aos sujeitos compreender o que lhes acontece e, assim, viver com a doença a longo prazo, apesar dos momentos de remissão ou de descanso durante os quais os pacientes não se sentem mais doentes. O evento de espera pelo diagnóstico médico e o vir a ser da doença acentua assim os movimentos de tomada de consciência da dramática temporalidade do sujeito. De fato, este evento abre horizontes sombrios que precipitam o sujeito em sua condição temporal de conviver com a morte no horizonte. Tal provocação leva o sujeito a revisitar suas posturas: como reagir? Muitas são as narrativas que recorrem a metáforas de guerra (luta, combate), em referência a Sontag (2009), ou evocam a violência, a raiva, o ódio de si para significar o estado emocional no qual os pacientes se encontram quando tomam conhecimento de sua doença. Em seguida, começa o desejo de saber, em particular, de lutar melhor ou de viver melhor com ele. Entretanto, para Picard (2009, p. 20):

as coisas só existem enquanto fazem sentido, ou seja, as intenções ou os projetos para o futuro são gradualmente preenchidos pelo movimento progressivo de objetivação da temporalização. O futuro é o meio pelo qual o passado toma forma e figura - deixa de ser vivido para ser conhecido. [Assim] todo conhecimento é definido como conhecimento de horizontes ou como perspectiva.

Portanto, é possível compreender melhor o que faz Louise dizer que, apesar da "paulada" que recebeu, ela paradoxalmente se sentiu "aliviada". Seu horizonte de significado e as perspectivas acabam se tornando, pelo menos, imagináveis, na falta de tornar-se a pessoa que ela gostaria de ter sido. Basicamente, esta ideia de que são as experiências, e não o sujeito em si mesmo, que abrem novos horizontes e proporcionam ao sujeito que as vive a possibilidade de se tornar ele mesmo, une-se à ideia de Romano $(2012$, p. 192) que fala da ex-per-iência. "[...] ex-per-iência é a condição de toda compreensão de si mesmo e do mundo tal como está enraizado nos acontecimentos". 
Através da narração escrita da experiência vivida de aguardar pelos resultados dos exames médicos, Louise experimenta a sua própria temporalidade e, poderíamos dizer, ela experimenta não apenas a sua própria temporalidade, mas também a redução dessa temporalidade. De fato, a espera é seguida pelo veredicto do diagnóstico, reduzindo a margem de sonhos e projetos possíveis quando se tinha apenas 20 anos de idade.

Quando os resultados saíram, eu não tinha nada a fazer, me senti frustrada, mas ao mesmo tempo aliviada, porque estava em estado de choque. Tinha acabado de saber que estava doente aos 18 anos e para toda a vida, minha vida estava arruinada, meus estudos STAPS $S^{5}$.. Eu tinha levado uma paulada na cabeça. Minha mãe agendou todas as consultas médicas, começou a tentar administrar a minha vida. Minha reação foi estúpida, eu teimosamente não escutei, fingi que nada aconteceu, não tomei minha medicação regularmente, fui para a cama tarde da noite. Esse periodo foi realmente uma chatice para mim (Louise).

Estas palavras ecoam em um dos últimos textos de Ricoeur (2005, p. 446): "a identidade pessoal é marcada por uma temporalidade que pode ser dita constitutiva. A pessoa é a sua história". Assim, às capacidades de dizer e agir, soma-se, fundamentalmente, a capacidade de narrar, que ocupa um "lugar eminente na medida em que eventos de todas as origens só se tornam legíveis e inteligíveis quando são contados em histórias... A construção narrativa produz uma bifurcação na própria identidade - que não é mais simplesmente a da mesma pessoa e inclui a mudança como um evento" (RICOUER, 2005, p. 447).

Em última análise, a história de um momento da vida, ou mesmo a história de uma vida, está em constante mudança através da refiguração "de todas as histórias verdadeiras ou fictícias que um sujeito conta sobre si mesmo" (RICOEUR, 1985, p. 356). Para Ricoeur, é precisamente o entendimento da vida como "um tecido de histórias contadas" e o acesso às narrativas que torna possível que a vida seja examinada e que o indivíduo se conheça.

5 Sigla que significa "Sciences et Techniques des Activités Physiques et Sportives" (Ciências e Técnicas de Atividades Físicas e Esportivas). Trata-se de um diploma superior que prepara futuros profissionais para atuarem na área do esporte, do treinamento esportivo, da motricidade, da ergonomia e da educação. 


\section{Elementos de perspectiva: passar da experiência temporal dolorosamente vivida para $o$ autocuidado}

Diante da doença, portanto, a questão do cuidado surge desde o início. $\mathrm{Na}$ medicina, a cura anda de mãos dadas com a doença, a menos que ela se mostre totalmente impotente. Também aqui, as dimensões temporais provam ser fundamentais. Worms (2014) destaca este aspecto fundamental do tempo inerente às dificuldades da vida: "Toda dificuldade em nossas vidas também se traduzirá em uma consciência do tempo, não mais como contato, mas como separação, o tempo como distância, que é também um sofrimento" (WORMS, 2014, p. 151). Os textos de Louise nos dão uma visão destas tomadas de consciência, destas separações do rumo habitual que uma vida pode tomar sem armadilhas, sem estes sofrimentos. Viver com uma doença de longo prazo, mesmo que o aspecto "crônico" mostre-se diversificado e descontínuo, como ressaltou Lecordier (2019), implica uma radicalização da relação com o tempo na pessoa doente.

A reflexão nos leva a considerar a profundidade do argumento de Picard (2009, p. 24): "O retorno sobre si mesmo só é realmente possível se fizermos do tempo uma dialética".

Além disso, este tempo dialético convida a apreender seus desafios em termos de cuidado. Portanto, juntamo-nos a Worms (2014, p. 152), para quem: "O cuidado não poderá, portanto, consistir em uma relação externa com o tempo, uma expectativa ou uma promessa, mesmo de cura". Em outras palavras, narrar uma provação refere-se ao tempo interior, subjetivo, vivido e experimentado dentro de si mesmo. Nesse contexto, novamente, a narrativa de Louise nos faz tocar na experiência de tempo em sua vida. As análises realizadas para entender o que ela experimentou através da sua narrativa nos convidam a ver o quanto: "Escrever não é certamente impor uma forma sobre uma matéria vivida. (...) É um processo, ou seja, uma passagem da Vida que atravessa o habitável e o vivido" (DELEUZE, 1993, p. 11-12). Este processo de escrita refere-se a uma transformação do eu que dá origem a uma vida ou a uma parte da vida, cuja singularidade ressoa com a dos outros. A história escrita pela pessoa sempre aparecerá contra a história escrita por outros em seu lugar. Essa forma de resistência é então entendida como "preocupação consigo" contra a biopoder (FOUCAULT, 1994).

Mas, como aponta Worms (2014, p. 257), para além de dar à história uma voz singular, trata-se também de ouvir o que a pessoa está pensando. "Não se trata apenas de ouvir a "sua voz", mas também de dar-lhe um lugar no concerto das vozes humanas, na discussão, sobretudo, na decisão, quando é disputada, por vezes trágica (como aqui) e que, além disso, lhe diz respeito". 
A leitura da narrativa de Louise só faz sentido se permitirmos que sua história nos alcance, nos afete, possibilitando que reflitamos sobre o pensamento da autora, para que, em diálogo e discussão, possam surgir novos horizontes de cuidado, colocados sob o signo da relação humana inscrita no coração das provas do tempo. Através de seu texto, não só conseguimos tocar de perto a dialética do tempo em um "cuidar de si mesmo" que necessariamente envolve uma relação com o outro, com os outros, mas também para que aprendamos com ele uma "lição de vida", em consonância com Stiker (2017, p. 182), para quem a condição de deficiente é "emblemática da condição de todos os seres humanos".

\section{REFERÊNCIAS}

BARDIN, Laurence. L'analyse de contenu. Paris: PUF, 2013.

BARRIER, Philippe. L'auto-normativité du patient chronique: approche méthodologique : implication pour l'Education Thérapeutique du patient. 2007. (Thèse de doctorat en Sciences de l'éducation) - Université de Paris 5, Paris, 2007.

BARTHES, Roland. Encore le corps. Paris: Seuil, 2002. (Euvres complètes V).

BERNET, Rudolf. Origine du temps et temps originaire chez Husserl et Heidegger. Revue Philosophique de Louvain, Louvain-la-Neuve, Belgique, n. 68, p. 499-521, 1987.

BILLOUET, Pierre. L'éducation scripturale. De la plume au clavier. Paris : L'Harmattan, 2010.

BOURRÉ-TESSIER, Josiane. Prolongation de l'intervalle QT corrigé chez les adultes atteints de Lupus érythémateux disséminé porteurs de l'anticorps anti-Ro/SSA. 2011. (Maître ès sciences) - Faculté de Médecine, Université de Montréal, Montréal, 2011.

BRETON, Hervé. L'enquête narrative : entre durée et détails. Education permanente. Cadernos de Pesquisa, São Paulo, v. 50, 178, p. 1138-1158, out./dez. 2020.

DELEUZE, Gilles. Critique et clinique. Paris: Minuit, 1993.

DELORY-MOMBERGER, Christine. La condition biographique. Essais sur le récit de soi dans la modernité avancée. Paris : Téraèdre, 2009.

DELORY-MOMBERGER, Christine. De la recherche biographique. Fondements, méthodes, pratiques. Paris: Téraèdre, 2014.

DELORY-MOMBERGER, Christine (dir.). Entretien de recherche biographique. In : Vocabulaire des histoires de vie et de la recherche biographique. Toulouse: Ėrès, 2019.

DEPRAZ, Natalie. Plus sur Husserl. Une phénoménologie expérientielle. Paris: Atlande, 2009. 
DEPRAZ, Natalie. L'éloquence en première personne. Alter, s.l., n. 19, p. 57-64, 2011.

FLORA, Luigi. Savoirs expérientiels des malades, pratiques collaboratives avec les professionnels de santé: état des lieux. Education permanente, n. 195, p. 59-72, 2013.

FOUCAULT, Michel. Dits et écrits. Paris: Gallimard, 1994.

GILLIGAN, Carol. Une voix différente. Paris: Flammarion, 2008.

HOUSSET, Emmanuel. Personne et sujet chez Husserl. Paris: PUF, 1997.

HUSSERL, Edmund. Leçons pour une conscience intime du temps. Paris: PUF, 1964.

HUSSERL, Edmund. Méditations cartésiennes. Paris: Vrin, 1980.

JOUET, Emmanuelle ; FLORA, Luigi ; LAS VERGNAS, Olivier. Construction et reconnaissance des savoirs expérientiels des patients: Note de synthèse. Pratiques de Formation - Analyses, Saint-Denis [Université Paris 8], p. 58-59, 2010.

LECORDIER, Didier. Les intermittents de la maladie. Analyse sociologique du vécu des personnes atteintes d'une maladie chronique. 2019. (Thèse de doctorat en Sociologie) - Université de Nantes, Nantes, 2019.

NIEWIADOMSKI, Christophe. Récit de vie. In : DELORY-MOMBERGER, Christine (dir.). Vocabulaire des histoires de vie et de la recherche biographique. Toulouse: Erès, 2019. p. 136-139.

PENEFF, Jean. La méthode biographique. De l'école de Chicago à l'histoire orale. Paris : A. Colin, 1990.

PETITMENGIN, Claire. La dynamique préréfléchie de l'expérience vécue. Alter, s.l., n. 18, p. 165-182, 2010.

PICARD, Yvonne. Le temps chez Husserl et Heidegger. Revue: Philosophie, s.l., n. 100 , p. 7-37, 2001.

RICOEUR, Paul. Temps et récit. III. Le temps raconté. Pairs : Seuil, 1985.

RICOEUR, Paul. Anthropologie philosophique. Écrits et conférences 3. Paris : Seuil, 2005.

ROMANO, Claude. L'événement et le temps. Paris: PUF, 2012.

ROSSI, Silvia. Écrire le cancer. De l'expérience de la maladie à l'autopathographie. Paris: Téraèdre, 2019.

SONTAG, Susan. La maladie comme métaphore. Paris : Seuil, 2009.

STIKER, Henri-Jacques. La condition handicapée. Grenoble: PUG, 2017.

TOURETTE-TURGIS, Catherine. L'activité de maintien de soi en vie et son accompagnement : un nouveau champ de recherche en éducation. Habilitation à diriger des recherches, Sciences de l'éducation. Paris: Cnam/Université Paris 13, 2013. 
VERMERSH, Pierre. L'entretien d'explicitation. Paris: ESF, 1994.

WORMS, Frédéric. Penser à quelqu'un. Paris: Flammarion, 2014.

WORMS, Frédéric. Le Moment du soin. À quoi tenons-nous ? Paris : PUF, 2010.

Texto recebido em 21/10/2020.

Texto aprovado em 05/12/2020. 